\title{
Cardiac MRI for the assessment of early chemotherapeutic cardiac injury and toxicity
}

\author{
Bina Franklin ${ }^{1 *}$, Veronica Fernandes ${ }^{2}$ \\ From 18th Annual SCMR Scientific Sessions \\ Nice, France. 4-7 February 2015
}

\begin{abstract}
Background
Chemotherapeutically induced myocardial injury continues to pose a major problem. The exact mechanism of drug-related cardiomyopathy (DRC) is still poorly understood. An early diagnosis of cardiotoxicity and the ability to predict patients at risk are important for preventing chronic heart failure. The guidelines for noninvasive cardiac imaging to screen for DRC show limitations in early identification of patients at risk, currently relying on left ventricular (LV) ejection fraction (EF) for establishing high risk. Contrast enhanced cardiac magnetic resonance imaging (ce-CMR) may offer a stronger screening approach, especially since it can assess the right ventricle (RV) and detect early changes in response to chemotherapy.
\end{abstract}

\section{Methods}

51 patients ( 31 men, 20 women) with various types of cancer, who underwent chemotherapy with a variety of regimens, were assessed with ce-CMR within 6 months of chemotherapy. Ce-CMR results for both RV and LV were compared with published data (Hudsmith et al., JACC, 2005) using the 1-sample Student t test. A p value $<0.05$ was considered significant. Descriptive statistics are described as percentages.

\section{Results}

In patients, $E F$ was lower in both ventricles: RVEF $=54.8 \%$ and $L V E F=53.6 \%$ vs. controls: $R V E F=61 \%$ and $\mathrm{LVEF}=69 \%,(\mathrm{p}=0.002, \mathrm{p}<0.001$, respectively). Right and left stroke volumes (SV) were also lower: RVSV= $69.1 \mathrm{~mL}, \mathrm{LVSV}=76.3 \mathrm{~mL}$, vs. controls: RVSV and LVSV $=104 \mathrm{~mL}(\mathrm{p} \leq 0.001)$. Both ventricles demonstrated decreased end diastolic volumes (EDV): RVEDV $=132.8$ $\mathrm{ml}$, LVEDV $=144.4 \mathrm{ml}$, vs. controls: $\mathrm{RVEDV}=173 \mathrm{ml}$

${ }^{1}$ Nuclear Medicine, Mount Sinai Hospital, New York, NY, USA

Full list of author information is available at the end of the article and LVEDV $=150 \mathrm{ml}$, though only statistically significant in the RV $(\mathrm{p}<0.001)$. An elevated end systolic volume (ESV) was also noted: RVESV $=70.1 \mathrm{~mL}, \mathrm{LVESV}=67.4$ $\mathrm{mL}$ vs. controls: RVESV $=69 \mathrm{ml}$ and $\mathrm{LVESV}=47 \mathrm{ml}$, though only statistically significant in the LV $(\mathrm{p}<0.001)$.

Interestingly, with respect to wall motion abnormalities, 4 (8\%) patients demonstrated segmental abnormalities in the RV. In the LV, 15 patients (29\%) demonstrated wall motion abnormalities, involving multiple segments (13/15 at the base, 13/15 at mid level, and $14 / 15$ in the apex). Only 1 (2\%) patient demonstrated delayed enhancement (DE) in the RV, while 10 patients (20\%) demonstrated DE in the LV, also involving multiple segments: $10 / 10$ in the basal $L V, 8 / 10$ in the mid LV, and $7 / 10$ in the apex.

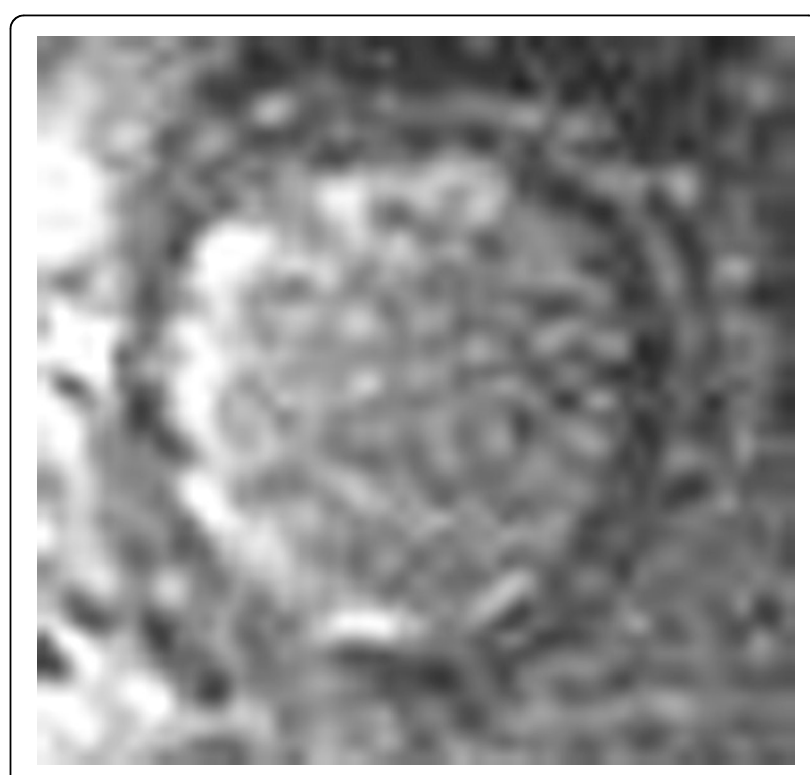

Figure 1 Delayed enhancement involving the left ventricle in a 61 year old male with Acute Myelogenous Leukemia. 


\section{Conclusions}

Decreased RVEF, LVEF and ventricular volumes, as well as wall motion abnormalities and presence of $\mathrm{DE}$ regions in non-coronary pattern of distribution, may represent early changes secondary to chemotherapy. Earlier detection of DRC may allow for earlier initiation of treatment, and prevent progression of heart failure.

\section{Funding}

None.

\section{Authors' details}

'Nuclear Medicine, Mount Sinai Hospital, New York, NY, USA. ${ }^{2}$ Mount Sinai Hospital, New York, NY, USA.

Published: 3 February 2015

doi:10.1186/1532-429X-17-S1-P370

Cite this article as: Franklin and Fernandes: Cardiac MRI for the

assessment of early chemotherapeutic cardiac injury and toxicity.

Journal of Cardiovascular Magnetic Resonance 2015 17(Suppl 1):P370.

Submit your next manuscript to BioMed Central and take full advantage of:

- Convenient online submission

- Thorough peer review

- No space constraints or color figure charges

- Immediate publication on acceptance

- Inclusion in PubMed, CAS, Scopus and Google Scholar

- Research which is freely available for redistribution

Submit your manuscript at www.biomedcentral.com/submit
C Biomed Central 